\title{
Redetermination of the crystal structure of pentastrontium trisilicide, $\mathrm{Sr}_{5} \mathrm{Si}_{3}$
}

\author{
R. Nesper and F. Zürcher \\ ETH Zürich, Laboratorium für Anorganische Chemie, Universitätstraße 6, CH-8092 Zürich, Switzerland
}

Received August 28, 1998, transferred to 1st update of database ICSD in 1999, CSD-No. 409376

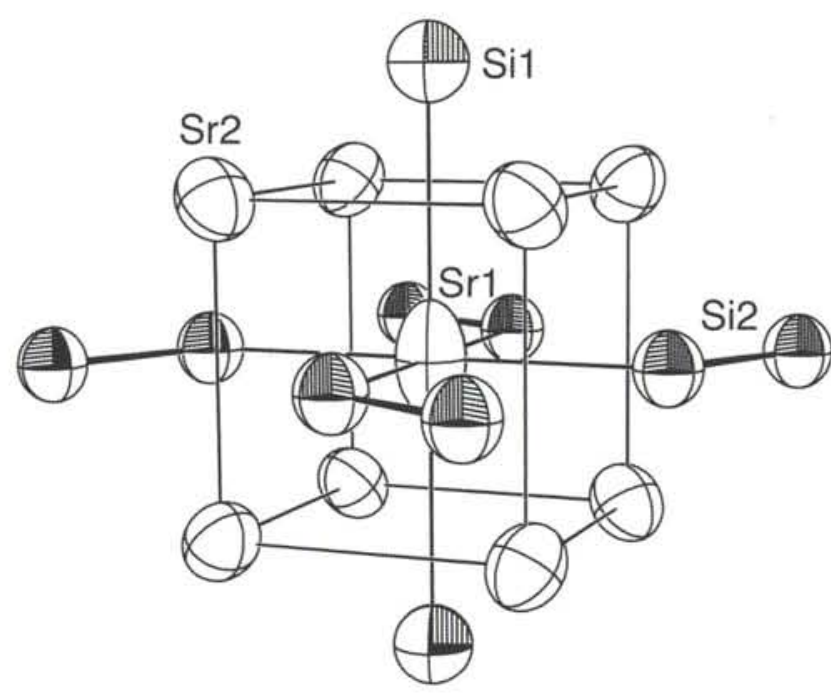

Abstract

Si 3 Sr5, tetragonal, $I 4 / m c m$ (No. 140), $a=8.089$ (4) $\AA$, $c=15.733(8) \AA, V=1029.4 \AA^{3}, Z=4, R_{\mathrm{gt}}(F)=0.029$, $R_{\mathrm{w}}\left(F^{2}\right)=0.055, T=298 \mathrm{~K}$.

\section{Source of material}

$\mathrm{Sr}_{5} \mathrm{Si}_{3}$ was prepared by heating a stoichiometric mixture of the elements at $1363 \mathrm{~K}$ ( $2 \mathrm{~d}$, cooling down within $10 \mathrm{~h})$. $\mathrm{Sr}_{5} \mathrm{Si}_{3}$ forms grey-black, plate-like crystals with a metallic lustre.

\begin{abstract}
Discussion
$\mathrm{Sr}_{5} \mathrm{Si}_{3}$ crystallises with the $\mathrm{Cr}_{5} \mathrm{~B}_{3}$ structure type in the space group $I 4 / \mathrm{mcm}$, and not in $14 \mathrm{~cm}$ as previously published [1]. The refinement in $I 4 \mathrm{~cm}$ did not lead to any improvements of the $R$ factors and the $\mathrm{Srl}$ atom hardly moves away from the mirror plane $(z=0.0003)$. Furthermore, strong correlations of positions that are symmetrically equivalent in $14 / \mathrm{mcm}$ are observed when the structure is refined in $14 \mathrm{~cm}$. Therefore, we chose $14 / \mathrm{mcm}$ to describe $\mathrm{Sr}_{5} \mathrm{Si}_{3}$, in contrast to the previously published structure [1]. $\mathrm{Sr}_{5} \mathrm{Si}_{3}$ contains $\mathrm{Si}_{2}{ }^{6-}$ dumb-bells and isolated $\mathrm{Si}^{4-}$ Zintl anions. It can be described, according to the Zintl-Klemm concept, by the formulation $\left(\mathrm{Sr}^{2+}\right)_{5}\left[\mathrm{Si}_{2}{ }^{6-}\right]\left[\mathrm{Si}^{4-}\right]$. The Si-Si bond distance in the dumb-bell is $2.47 \AA$. Srl is coordinated by four equatorial $\mathrm{Si} 2$ dumb-bells and two axial $\mathrm{Si} 1$ atoms forming a very elongated octahedron. This may be the reason for the large $U_{33}$ displacement parameter of $\mathrm{Sr} 1$.
\end{abstract}

Table 1. Data collection and handling.

$\begin{array}{ll}\text { Crystal: } & \text { black piece, size } 0.10 \times 0.15 \times 0.20 \mathrm{~mm} \\ \text { Wavelength: } & \text { Mo } K_{\alpha} \text { radiation }(0.71073 \AA) \\ \mu: & 260.08 \mathrm{~cm}^{-1} \\ \text { Diffractometer, scan mode: } & \text { Stoe STADI4, } \omega / \theta \\ 2 \theta_{\text {max: }} & 59.88^{\circ} \\ N(h k l)_{\text {measured, } N(h k l)_{\text {unique: }}} & 2900,425 \\ \text { Criterion for } I_{\text {obs }}, N(h k l)_{\text {gt: }} & I_{\text {obs }}>2 \sigma\left(I_{\text {obs }}\right), 336 \\ N(\text { param })_{\text {refined: }} & 16 \\ \text { Programs: } & \text { SHELXS-96 [2, SHELXL-96 [3], } \\ & \text { ORTEPII [4] }\end{array}$

Table 2. Atomic coordinates and displacement parameters (in $\AA^{2}$ ).

\begin{tabular}{|c|c|c|c|c|c|c|c|c|c|c|}
\hline Atom & Site & $x$ & $y$ & $z$ & $U_{11}$ & $U_{22}$ & $U_{33}$ & $U_{12}$ & $U_{13}$ & $U_{23}$ \\
\hline $\operatorname{Sr}(1)$ & $4 c$ & 0 & 0 & 0 & $0.0182(3)$ & $U_{11}$ & $0.0498(7)$ & 0 & 0 & 0 \\
\hline $\operatorname{Sr}(2)$ & $16 l$ & $0.17815(4)$ & $x+1 / 2$ & $0.14162(3)$ & $0.0211(2)$ & $U_{11}$ & $0.0227(2)$ & $0.0003(2)$ & $-0.0030(2)$ & $U_{13}$ \\
\hline $\operatorname{Si}(1)$ & $4 a$ & 0 & 0 & $1 / 4$ & $0.0233(9)$ & $U_{11}$ & $0.023(1)$ & 0 & 0 & 0 \\
\hline $\operatorname{Si}(2)$ & $8 h$ & $0.3919(2)$ & $x+1 / 2$ & 0 & $0.0172(6)$ & $U_{11}$ & $0.0200(9)$ & $-0.0003(7)$ & 0 & 0 \\
\hline
\end{tabular}

Acknowledgment. This work was supported by the Swiss National Foundation.

\section{References}

1. Nagorsen, G.; Rocktäschel, G.; Schäfer, H.; Weiss, A. : Die Kristallstruktur der Phase SrsSi3. Z. Naturforsch. 22b (1967) 101.
2. Sheldrick, G. M.: SHELXS-96. Program for the solution of crystal structures. University of Göttingen, Germany 1996.

3. Sheldrick, G. M.: SHELXL-96. Program for refining crystal structures. University of Göttingen, Germany 1996.

4. Larson. A.C.; Lee, F. L.; Le Page Y.; Webster, M.; Charland, J. P.; Gabe, E. J.: NRCVAX Crystal Structure System with interactive version of ORTEP II, NRC, Ottawa, Canada 1986. 